\title{
Alunos com déficit de atenção: 0 cotidiano em sala de aula
}

\section{ARTIGO DE REVISÃO}

SANTOS, Betina Pinto ${ }^{1}$

MIRANDA, Neire Oliveira Pinto ${ }^{2}$

SANTOS, Betina Pinto. MIRANDA, Neire Oliveira Pinto. Alunos com déficit de atenção: $O$ cotidiano em sala de aula. Revista Científica Multidisciplinar Núcleo do Conhecimento. Ano 05, Ed. 11, Vol. 15, pp. 106-117. Novembro de 2020. ISSN: 24480959, Link de acesso: https://www.nucleodoconhecimento.com.br/educacao/sala-deaula

\section{RESUMO}

O estudo buscou realizar uma abordagem referente ao cotidiano em sala de aula de alunos com déficit de atenção, através de uma revisão bibliográfica sobre como lidar com alunos que apresentam TDAH, apresentando a relevância dessa temática no atual contexto social e na relação ente memória e aprendizagem, objetivando contribuir com as mais diversas áreas do conhecimento, em especial com a área da educação. Este artigo tem como objetivo apresentar ao leitor a partir de estudo bibliográfico com bases teóricas sólidas, como alguns educadores desenvolvem um trabalho especial com crianças que possuem déficit de atenção. Para tanto, foi realizada uma pesquisa bibliográfica considerando as contribuições de autores como Ribeiro (2016), Russo (2015), Silva (2009), e Berger (2001), entre outros, procurando, levantar reflexões sobre as dificuldades em aprendizagem que são bastante frequentes nas escolas. Conclui-se que ainda que existam diversos procedimentos para a tomada de decisão diagnóstico de TDAH, a avaliação da patologia é essencialmente clínica. A criança diagnosticada com TDAH é um aluno que precisa de um atendimento específico, de suporte para desenvolver o seu aprendizado, um

\footnotetext{
${ }^{1}$ Pós graduada em Educação Infantil e Neuropsicopedagogia - Pedagogia.

2 Pós graduada em Psicopedagogia - Pedagogia.
} 
ambiente organizado, atividades curtas, lúdicas, atenção e compreensão por parte dos professores e deve se sentir querido e util. A aula deve ser animada e dinâmica, com uma linguagem simples e concreta, em que o aluno realmente entenda 0 conteúdo por sua facilidade.

Palavras-chave: Déficit de atenção, diagnóstico, sala de aula, educador.

\section{INTRODUÇÃO}

O presente trabalho tem como tema alunos com déficit de atenção: o cotidiano em sala de aula, apresentando a relevância dessa temática no atual contexto social e na relação entre memória e aprendizagem, com o objetivo de contribuir com as mais diversas áreas do conhecimento, em especial com a área da educação.

Nesta concepção, a pesquisa relevante ao tema, levou ao estudo sobre o transtorno de Déficit de Atenção e Hiperatividade em sala de aula.

As dificuldades em aprendizagem estão bastante frequentes nas escolas. $\mathrm{O}$ baixo nível cognitivo não decorre do ensino, ou da metodologia do professor que já usou todos os recursos cabíveis e não há avanços e é na escola onde os primeiros sinais acabam sendo percebidos, a partir desta descoberta, cabe uma investigação. Neste momento as intervenções devem ser tomadas. A criança necessita ser avaliado por um especialista, pois sós esses profissionais podem ajudá-los a superar as dificuldades, tendo um cuidado especial com essas crianças que muitas vezes são taxados de desprovido de inteligência.

Segundo Russo (2015) as dificuldades de aprendizagem podem derivar de causas emocionais, do nível de pensamento, de diferenças funcionais ou de alterações no desenvolvimento das funções, dessa forma, faz- se necessário a observação para uma ação pedagógica.

De acordo com Moojen; Dorneles e Costa (2003) os problemas de aprendizagem podem ser divididos em duas categorias: dificuldades específicas de aprendizagem (devido a problemas neurológicos) e dificuldades escolares, que podem ser 
secundárias a outras patologias clínicas (transtorno de déficit de atenção/hiperatividade, depressão, transtornos do humor) e ambientais Método de ensino do problema.

Quando o aluno apresenta dificuldades em concentrar, não para sentado, tem dificuldades em lidar com horários, inquietação, pessimismo, sempre desvia o olhar onde há movimentos, está sempre sabendo de tudo que acontece na sala, entendese que a mesma tem capacidades cognitiva e linguística, mas necessita de algo a mais para se situar no ambiente escolar possui dificuldade de manter as coisas organizadas, com esses sintomas ele poderá ser diagnosticado com déficit de atenção, pois é notório pelo seu comportamento.

O tema apresentado tem como objetivo principal, apresentar ao leitor a partir de estudo bibliográfico com bases teóricas sólidas, como alguns educadores desenvolvem um trabalho especial com crianças com déficit de atenção. $\mathrm{Na}$ concretude dos objetivos propostos foram consultados trabalhos metodológicos e pesquisas bibliográficas através de materiais já publicados em redes sociais.

O texto foi fundamentado nas ideias e concepções de autores como: Ribeiro (2016); Russo (2015); Silva (2009) e Berger (2001).

\section{A APRENDIZAGEM}

Para Vygotsky; Luria e Leontiev (2010) a aprendizagem se dá da interação com o homem e o meio e a escola é o campo intencional da aprendizagem, por isso a teoria recebeu o nome de teoria do sócio construtivismo, pois o conhecimento não brota, ele se constrói. O professor procura interagir a criança e o ambiente e ela internaliza produzindo o conhecimento. Para Paín (1985, p. 23) “A aprendizagem é um processo dinâmico que determina uma mudança..." É através da Educação que se constrói o sujeito.

De acordo com Pain (1985) a educação precisa de mudanças por isso faz se necessário conhecer o aluno e desenvolver um trabalho de forma que vem atender à 
necessidade neurológica e psicológica dentro da sala de aula e também sala de recursos/reforço escolar.

Vygotsky; Luria e Leontiev (2010, p. 106) também ressalta que a aprendizagem pode ser definida como sendo uma linha de abordagem segundo a qual:

O desenvolvimento mental da criança caracteriza-se por dois processos, que embora conexos, são de natureza diferente e condicionam-se reciprocamente. Por um lado, está a maturação, que depende diretamente do desenvolvimento do sistema nervoso, e por outro lado a aprendizagem que segundo Koffka, é em si mesmo o aprendizado.

Entende-se que a criança tem várias formas de chegar à aprendizagem usando todo o campo da memória, porém cada criança tem tempo certo de maturação para chegar lá.

Russo, (2015, p. 83) diz que "as dificuldades em aprendizagem podem derivar de causas emocionais, do nível do pensamento de diferenças funcionais ou de alterações no desenvolvimento das funções".

Entende-se que a criança já nasce com algumas funções psicológico-neurológica comprometida. Conforme a Organização Mundial de Saúde (1993 apud RUSSO, 2015, p. 84-85), na sua descrição diz que:

Os transtornos específicos do desenvolvimento das habilidades escolares compreendem grupos específicos de transtornos manifestados por comprometimentos e significativos na aprendizagem. [...] Eles não nãos simplesmente uma falta de oportunidade de aprender, e sim, dificuldades decorrentes de desenvolvimento neurológico.

Diante do exposto, é perceptível a necessidade de acompanhamento, pois a criança não deixa de aprender por um simples desinteresse, há sempre algo que o impede neste campo semântico.

Kandel (2009, p. 149) transcreve que:

Todo conhecimento que temos advindo da educação formal ou não, necessita permanecer em nossa memória para que seja considerado aprendizado, pois se não lembramos, é sinal que não aprendemos. 
Deste modo, aprendizagem tem íntima relação com memória e se não fosse por esse mecanismo, passaríamos cada minuto da nossa vida tendo de aprender.

Entende-se que a memória é o campo importante do cérebro, onde estão, armazenadas as nossas emoções, as nossas lembranças, o nosso aprendizado, sem memória não somos capazes de aprender. Russo (2015, p.17) descreve como o cérebro se apresenta e suas particularidades de funcionamento:

O cérebro apresenta uma série de dobras características na região do córtex. Essas dobras servem para aumentar a área de superfície dessa estrutura, que conta apenas com o espaço restrito da cavidade craniana. Os hemisférios cerebrais são divididos em quatro lobos, que recebem o nome de acordo com o osso do crânio situado acima dele: 1. Lobo Frontal: é o responsável pelos mais simples movimentos físicos, como também pelas funções do aprendizado, do pensamento, da memória e da fala, quando este não corresponde à perfeição aí se dá o déficit de atenção. 2. Lobo Parietal: ele é responsável pela percepção espacial e pelas informações sensoriais de dor, calor e frio. 3. Lobo temporal: é responsável pelos estímulos auditivos. 4. Lobo Occipital: está situado na parte posterior do temporal, recebe e processa as imagens visuais.

Entende-se que através da citação da autora o cérebro armazena e processa informação por isso ocorre a aprendizagem, pois é nele que está armazenado a parte cognitiva. Segundo Russo (2015) as neurociências cognitivas fornecem aos profissionais de saúde e de educação as bases teóricas sobre o funcionamento neurológico, e da plasticidade cerebral, o desenvolvimento e maturação cerebral, contribuindo significativamente para o desenvolvimento ensino aprendizagem. Os pesquisadores têm se debruçado ao estudo do cérebro e seu comportamento humano, dos fatores que interferem na aprendizagem e das técnicas de reabilitação cognitiva. Logo, a Neuropsicopedagogia a psicopedagogia tem a função de atender as crianças que apresentam dificuldades de aprendizagem além de outras patologias, um trabalho em parceria com outros especialistas, como fonoaudióloga, psicólogos, entre outros que se fizer necessário.

Segundo Ferreiro e Teberosk (1985) as crianças passam por diversas fases e nestas vão amadurecendo e se descobrindo, isso acontece quando é uma criança dita "normal". Queremos que as crianças sejam iguais, mas teremos situações que nos 
desespera e nos desperta para algo muito comum em sala; à criança com déficit de atenção. Estas crianças podem demorar mais o processo de ensino aprendizagem, elas precisam de atendimentos especiais por profissionais capacitados na área e de suporte para a que a mesma possa desenvolver suas habilidades na leitura e escrita.

Ferreira e Teberosk (1985) ainda destaca que as hipóteses infantis no processo de leitura dividem-se em fases: Fase das Garatujas: São os rabiscos realizados pela criança, ela não tem noção da escrita; Fase da Hipótese Pré-Silábica: Nessa fase a criança ainda não consegue associar a letra a sua sonoridade, escreve com poucas letras e acredita que escreveu corretamente. Fase da hipótese Silábica: Nessa fase a criança já consegue reproduzir algumas palavras e associa a sílaba ao som. Fase da Hipótese Silábica Alfabética: Nesta fase a criança consegue ler e escrever palavras e frases.

Neste contexto, a criança passa por várias fazes até chegar à aprendizagem umas aprendem com facilidade e outras levam mais tempo; de maneira alguma o professor deve rotular esta criança como um incapaz ou deixa-la de lado, elas precisam de uma dedicação exclusiva de um olhar especial sobre um todo; desenvolver sua linguagem e suas maneiras de descobrir o que realmente importa para o seu desenvolvimento cognitivo.

\section{COMO TRABALHAR EM SALA DE AULA}

O professor após perceber que seu aluno tem algum tipo de transtorno, deve ter uma atenção voltada a ele, elogiá-lo sempre por tudo que ele conseguir fazer ou pelo menos tentar fazer, incentivando sempre. O incentivo é fundamental, tendo em vista que para este é extremamente penoso à execução das tarefas proposta. Para o aluno com dificuldades em aprendizagem é necessário que o professor inicie uma reflexão acerca dos métodos de ensino, refletindo sobre os aspectos teóricos e psicológicos.

Para o auxílio dos métodos de ensino na sala de aula os profissionais Hallowell e Ratey (1999, p. 31) propõe algumas sugestões: 
Saber ao certo que é uma criança com Distúrbio do Déficit de Atenção (DDA) que está lidando; busque suporte para trabalho; interagir constantemente com a mesma; estabelecer limites de maneira simples e consistente e não de forma punitiva; buscar a qualidade e não a quantidade, alunos com DDA precisam de uma carga de trabalho reduzida; dividir as tarefas longas em curtas; valorizá-las, durante e após suas tarefas; ensinar de forma ilustrativa, atividades com desenhos e cores, as crianças aprendem melhor o que está escrito; simplificar o que é dito; desenvolver as responsabilidades delas; levar ao conhecimento dos colegas da sala sobre o distúrbio que o outro apresenta; interagir com os pais desta criança.

Além dos métodos o professor deverá trabalhar com jogos, pois eles facilitam o desenvolvimento do seu raciocínio lógico, desenvolve a concentração. Um dos dispositivos a ser usado com muito sucesso são as atividades/jogos online, elas gostam e o tempo de concentração é mais longo (divertido).

\section{VISÃO SOBRE DÉFICIT DE ATENÇÃO}

Há mais de um século a literatura estuda este distúrbio como um transtorno neurobiológico de causas genéticas ambientais e hereditária causando incapacidade de modular respostas ao estímulo, com impulsividade e, desatenção, baixa autoestima, provocando um grande impacto na vida da criança.

A educação passou de fato por transformações no advento da burguesia industrial, urbana e as consequentes licitações de ampliação de oferta de ensino, ensino esse limitados a pessoas ditas normais As famílias com crianças com alguma deficiência arcavam com todo o ônus de tentar tornar seus filhos alunos participantes e ativos do processo pedagógico e social da escola, pois os deficientes físico, mental ou qualquer outro distúrbio era abolido da sociedade (SILVA, 2009).

Como resultado da Conferência Mundial sobre Necessidades Educacionais Especiais, realizada entre sete e 10 de junho de 1994, na cidade espanhola de Salamanca, no seu contexto a Declaração de Salamanca trata de princípios, políticas e práticas na área das necessidades educativas especiais e aborda que:

Os Direitos humanos e a Declaração Mundial sobre a Educação para Todos e aponta os princípios de uma educação especial e de uma 
pedagogia centrada na criança. Em seguida apresenta propostas, direções e recomendações da Estrutura de Ação em Educação Especial, um novo pensar em educação especial, com orientações para ações em nível nacional e em níveis regionais e internacionais (PAPADOPOULOS, 2018, p. 110).

De acordo com o texto fica evidente que toda criança com necessidades especiais tem os mesmos direitos das crianças "normais" para os padrões da sociedade.

A inclusão de crianças, jovens e adultos com necessidades educacionais especiais dentro do sistema regular de ensino é a questão central, sobre a qual a Declaração de Salamanca discorre. Diante disso passou se a pensar muna educação como um todo refletindo sua importância para a criança na sua individualidade, todos tem direitos iguais independente de raça, cor, condições sociais. Foi na constituição Federal de 1988 que se consagrou direitos a todos e a partir da lei 8.069/90 do estatuto da criança e do adolescente tornou-se de fato cobrada, conforme Estatuto da Criança e do Adolescente (ECA) (PACIEVITCH, 2009).

Art. 53. A criança e o adolescente têm direito à educação, visando ao pleno desenvolvimento de sua pessoa, preparo para o exercício da cidadania e qualificação para o trabalho, assegurando-se Ihes: I igualdade de condições para o acesso e permanência na escola; II direito de ser respeitado por seus educadores; III - atendimento educacional especializado aos portadores de deficiência, preferencialmente na rede regular de ensino (BRASIL, 1990).

Porém havia algo a mais a ser feito, as crianças com deficiência, que era aceita somente em instituições como APAE, ADATA deveriam ter o acesso à escola normal, juntos com as outras crianças para convierem e aprenderem a socializar então surgia a Lei $\mathrm{n}^{0}$ 13.146, de seis de julho de 2015 (PACIEVITCH, 2009).

A Lei $\mathrm{n}^{0}$ 13.146, de seis de julho de 2015, traz:

Art. 1ํ. É instituída a Lei Brasileira de Inclusão da Pessoa com Deficiência (Estatuto da Pessoa com Deficiência), destinada a assegurar e a promover, em condições de igualdade, o exercício dos direitos e das liberdades fundamentais por pessoa com deficiência, visando à sua inclusão social e cidadania. Art. $2^{\circ}$. Considera-se pessoa com deficiência aquela que tem impedimento de longo prazo de natureza física, mental, intelectual ou sensorial, o qual, em interação com uma ou mais barreiras, 
pode obstruir sua participação plena e efetiva na sociedade em igualdade de condições com as demais pessoas (BRASIL, 2015).

Segundo, George Still, pediatra inglês, em Londres, utilizou de vários termos para definir o déficit de atenção tais como:

Defeito da Conduta Moral". Já nos anos de 1930 a 1940 o termo utilizado foi Danos Cerebrais e Disfunção Cerebral. A partir de 1960 começam a surgir novas terminologias na literatura. Em 1968, o DSM-II utilizou o termo Reação Hipercinética e em 1978 o CID-9 2 usou Transtorno Hipercinético. Em 1980 o DSM-III utilizou Transtorno do Déficit de Atenção com ou sem Hiperatividade - aparecendo pela primeira vez a desatenção como característica. Em 1987 o DSMIII-R usou Transtorno do Déficit de Atenção com Hiperatividade e em 1992 o CID-10 utilizou Transtornos Hipercinéticos. O termo mais usado nos dias de hoje, através do DSM-IV3, passou a ser: Transtorno do Déficit de Atenção e Hiperatividade - dividido em três subtipos: tipo desatento, hiperativo/impulsivo e o combinado (BARBOSA; DIAS; GAIÃO, 1997, p. 119).

Após vários termos, hoje o TDAH é conhecido por todos os profissionais da área de Educação e no ambiente escolar, porém é comum nas escolas crianças com sintomas e muitas vezes sem o diagnóstico, às vezes a família não aceita, dificultando o seu desempenho acadêmico.

Para Silva (2009, p. 12) o TDAH se caracteriza por três sintomas básicos:

Desatenção, impulsividade e hiperatividade física e mental. Costuma se manifestar ainda na infância e em cerca de $70 \%$ dos casos o transtorno continua na vida adulta. Ele acomete ambos os sexos, independentemente do grau de escolaridade, situação socioeconômica ou nível cultural, o que pode resultar em sérios prejuízos na qualidade de vida das pessoas que têm, caso não sejam diagnosticadas e orientadas precocemente.

Nesta perspectiva entende-se que os sintomas são identificados precocemente na sala da aula pelo professor que consequentemente busca alternativas para a solução do problema.

\section{DIAGNÓSTICO}


O diagnóstico do TDAH é clinico e o melhor período para uma avaliação é na infância quando a criança começa a ser alfabetizada aos seis anos de idade e começa demostrar os primeiros sintomas, pede uma intercessão por profissionais especializados, buscando informações recolhida através dos pais, professores, psicopedagogo, através da anamnese e várias sessões de terapia para posteriormente movimentar-se médicos, psicólogo, fonoaudiólogo, neurologista e/ou psiquiatra, até chegar ao diagnóstico final e posteriormente o acompanhamento.

Para chegar ao diagnóstico é necessário fazer ANAMNESE realizando entrevistas com os pais com o objetivo de conhecer o histórico familiar e da criança desde período de gestação da mãe até os dias atuais, entender de fato o que levou a criança a este transtorno. Entrevista com o professor para conhecer o comportamento da criança na escola, o seu desempenho escolar, como se relaciona com os colegas em sala de aula e fora da sala, questionários com perguntas especificas a serem preenchidos pelos pais, posteriormente a criança será encaminhada para avaliação neuropsicológica; avaliação psicopedagógica; avaliação fonoaudiologia caso necessário.

O tratamento em alguns casos necessita de medicamentos controlado com o objetivo de serenar (acalmar) a criança agitada e melhorar a concentração. Um remédio mais indicado é a RITALINA (metilfenidato) que pode ser adquirido somente com retenção de receita (remédio controlado pela OMS). O mesmo pode causar alguns sintomas como sonolência e desânimo etc. Deve se ter um acompanhamento por especialista, pois a tratamento bem aplicado e acompanhado por especialista tem ótimos resultados. Logo, o reconhecimento, o apoio e incentivo vindo dos pais e professores são essenciais para que a criança tenha um bom funcionamento, seja criativo, tenha autoestima positiva e equilibrada (RIBEIRO, 2016).

Segundo Berger (2001, p. 208):

As crianças com diagnóstico de TDAH precisam de ajuda para superar alguns fatores como: uma percepção confusa sobre o mundo social; o desprezo que sentem sobre si mesmas; um déficit de atenção e aumentar a capacidade de memória. Isto porque tais fatores podem ser 
decisivos como geradores de consequências desagradáveis ao processo de aprendizagem escolar.

Família, base da sociedade, base da educação, amor, afeto, carinho, princípio religioso, base dos princípios morais e éticos, é de suma importância na educação dos filhos. A família e a escola devem andar de mãos dadas, principalmente quando se trata de uma criança com TDAH, elas devem participar juntas do desenvolvimento intelectual, psicológico e cognitivo da criança, dando feedback de tudo o que acontece (BERGER, 2001).

Russell et al. (2000, p. 30) fala sobre a importância dos pais formarem um grupo de apoio para ajuda-los, através da troca de experiência entre si e descobrindo novas formas de resolver conflitos existenciais onde terá a participação de profissionais para palestras e oficinas, um centro de apoio para os mesmos, baseando em programas fundamentados na aprendizagem social, na psicologia social-cognitiva, na teoria de sistemas familiares. "A escola deve ter noção e preparar seus professores com treinamentos e dar-Ihes suporte de outros profissionais, mantendo comunicação entre família e escola e realização da mesma" (RUSSELL et al., 2000).

\section{CONSIDERAÇÕES FINAIS}

Dificuldades escolares constituem queixa frequente, sendo motivo de encaminhamento a especialistas. O transtorno do déficit de atenção e hiperatividade (TDAH) merece ser investigado e adequadamente tratado. O TDAH repercute na vida da criança e do adolescente levando a prejuízos em múltiplas áreas, como a adaptação ao ambiente acadêmico, relações interpessoais e desempenho escolar.

A avaliação psicológica e o diagnóstico do TDAH envolvem um processo delicado e de difícil compreensão, o qual demanda da ajuda de profissional, experiência clínica, um bom conhecimento teórico e, sem dúvida, muita reflexão. É importante que o professor saiba o que é TDAH e como trabalhar com criança com esse transtorno.

Conclui-se que ainda que existam diversos procedimentos para a tomada de decisão diagnóstico de TDAH, a avaliação da patologia é essencialmente clínica. A criança 
diagnosticada com TDAH é um aluno que precisa de um atendimento específico, de suporte para desenvolver o seu aprendizado, precisa de um ambiente organizado, atividades curtas, lúdicas; precisa de atenção e compreensão por parte dos professores, precisa sentir querido e util. A aula deve ser animada e dinâmica, com uma linguagem simples e concreta, em que o aluno realmente entenda o conteúdo por sua facilidade.

\section{REFERÊNCIAS}

BARBOSA, G. A.; DIAS, M. R.; GAIÃO, A. A. Validacíon factorial de los índices de hiperatividade del cuestionário de Conners en escolares de Jõao Pessoa 3/4 Brasil. Infanto; v. 5, n. 1, p.118-125, 1997.

BERGER, K. S. O desenvolvimento da pessoa: da infância à terceira idade. Tradução de Dalton Conde de Alencar. 5. ed. Rio de Janeiro: LTC, 2001.

BRASIL. Previdência da República. Lei no 13.146, de 6 de julho de 2015. Institui a Lei Brasileira de Inclusão da Pessoa com Deficiência (Estatuto da Pessoa com Deficiência). Disponível em: <http://www.planalto.gov.br/ccivil_03/_ato20152018/2015/lei//13146.htm>. Acesso em: 30 nov. 2019.

Previdência da República. Lei no 8.069, de 13 de julho de 1990. Dispõe sobre o Estatuto da Criança e do Adolescente e dá outras providências. Disponível em: <http://www.planalto.gov.br/ccivil_03/leis//8069.htm>. Acesso em: 30 nov. 2019.

FERREIRO, Emilia; TEBEROSK, Ana. A Psicogênese da Língua Escrita. Porto Alegre: Artes Medicas 1985.

HALLOWELL, Edward M.; RATEY, John J. Tendência à distração: identificação e gerência do distúrbio do déficit de atenção (DDA) da infância à vida adulta. Trad. André Carvalho. Rio de Janeiro: Rocco,1999. 
MOOJEN, S. M.; DORNELES, B. V.; COSTA, A. Avaliação psicopedagógica no TDAH. In: Rohde LA e Mattos $P$ (eds.) Princípios e Práticas em TDAH. Artmed, Porto Alegre, pp. 107-16, 2003.

PACIEVITCH, Thais. Declaração de Salamanca. 2009. Disponível em: $<$ https://www.infoescola.com/educacao/declaracao-de-salamanca/>. Acesso em: 30 nov. 2019.

PAÍN, Sara. Diagnóstico e tratamento dos problemas de aprendizagem. Tradução Ana Maria Netto Machado. Porto Alegre: Artmed, 1985.

PAPADOPOULOS, Cátia Regina. A trajetória acadêmica de estudantes universitários diagnosticados com TDAH à luz da Teoria Bioecológica do Desenvolvimento Humano. 2018. 184p. Tese (doutorado)-Pontifícia Universidade Católica do Rio de Janeiro, Departamento de Educação, 2018.

RIBEIRO, Simone Pletz. TCC e as funções executivas em crianças com TDAH. Revista Brasileira de Terapias Cognitivas; v. 12; n. 2; p.126-134, 2016.

RUSSELL, A. Barkley et al. Transtorno de déficit de atenção/hiperatividade: Manual para diagnóstico e tratamento. Editora Artmed Editora, 2000.

RUSSO Rita Margarida Toler. Neuropsicopedagogia Clinica, Introdução, Conceitos, Teoria e Prática. JURUÁ Psicologia, Curitiba, 2015.

SILVA, Ana Beatriz Barbosa. Mentes inquietas: TDAH: desatenção, hiperatividade e impulsividade. Rio de Janeiro: Objetiva, 2009.

VIGOSTKY, L.; LURIA, A.; LEONTIEV, A. N. Desenvolvimento e Aprendizagem.

Enviado: Março, 2020.

Aprovado: Novembro, 2020. 